\title{
Computed tomography angiography on the stifle region of the sheep
}

\author{
Iliana Ruzhanova ${ }^{1}$, Konstantin Aminkov², Bogdan Aminkov² \\ 1. Department "Anatomy, histology and physiology", University \\ of Forestry, Faculty of Veterinary Medicine - Sofia; \\ 2. Department of Surgery, Radiology, Obstetrics and \\ Gynecology; University of Forestry, Faculty of Veterinary \\ Medicine, Sofia;
}

\begin{abstract}
The purpose of this research is the observation of the blood vessels in the knee region of the sheep by computed tomography angiography. Four female lambs were examined. After providing operational access to a. femoralis catheter we introduced a catheter into the artery. We used the method spiral computed tomography to carry out the computer-based imaging. The spiral CT scanning was performed in transverse planes starting from the middle of the femur to the middle of the tibia. The slices were $1.5 \mathrm{~mm}$ thick, at $2 \mathrm{~mm}$ intervals. The scanning was done using computer software. The arteries and the veins in the knee region of the sheep are visualized as CT images (slices). The popliteal artery and vein, saphenous artery, medial saphenous vein are of utmost importance; in ruminants in particular, the lateral saphenous vein and a. genus media that are responsible for the blood supply to the cruciate ligaments. CT angiography is recommended for the diagnosis and monitoring of the impaired vascularization of the stifle joint structures of the sheep, which is supported by the results of this study.
\end{abstract}

Keywords: computed tomography, stifle joint, popliteal artery and vein, sheep.

\section{Introduction}

Animals are commonly used as models for the study of new treatment options of knee joint injuries, including joint meniscus injuries (Takroni et al., 1997). The sheep compared to pigs and rabbits is 
considered as a more appropriate animal for testing new therapeutic regimens in humans' meniscal surgery (Takroni et al., 1997, Saitz et al., 1997, Chevrier et al., 2009). Sheep meniscus is similar to the human one by length, width, weight, vascularization and collagen structure (Chevrier et al., 2009). The knee joint of the sheep is of the utmost importance for the studies concerning the recovery of articular cartilage defects in large animals and people (Saitz et al., 1997, Orth and Madry, 2013).

The blood supply to the knee joint is of great significance in the cases of traumas of its various structures, as well as for the surgery, orthopedics and treatment of the injuries of the same area (Saitz et al., 1997). The blood vessels of mammals are branches of a. and v. poplitea (Getty, 1975; Schaller, 2007; Ashdown and Done, 2010). V. saphena medialis (magna) and V. saphena lateralis (parva) are superficially accessible for venipuncture of the pelvic limb (Evans and de Lahunta, 2013). They are described by May (1955), and later by other authors: Schaller (2007), Ashdown and Done (2010). Various authors have examined the veins of the limbs of cattle, sheep and goat by digital phlebography (Santos et al., 2016). The veins of the limbs of the goat have been examined by arteriography as well (Burns and Cornell, 1981; Nazhvani, 2007), visualizing the vessels predominantly of the digits and in the metacarpal and metatarsal regions (Nazhvani, 2007; Santos et al., 2016). Angiographic studies can be used to diagnose a variety of vascular diseases of the digits and hoof in the cattle, such as regional thrombosis, alter circulation in the dermis, undeveloped arterial arches and little or no arterial enlargement in corium coronae (Gantke et al., 1998, Nazhvani et al. ., 2007). Pathological changes in dairy cattle's chronic laminitis have been detected by arteriography (Maclean, 1970; Boosman et al., 1998; Vermunt and Greenough, 1994; Nazhvani et al., 2007). The formation of the portal vein, its intrahepatic branches, hepatic veins, and the branches of $a$. celliaca in ruminants was observed by contrast computed tomography of lambs by Georgiev et al. (2012). Computed tomography angiography and gross anatomical dissection were performed to describe the angiographic anatomy of the external iliac arteries of the sheep and to compare them to human's. (Joscht et al., 2016).

The diagnosis of osteoarthritic changes has been made by detecting the joint cartilage defects of the trochlea femoris, kneecap, lateral and medial condyles of tibia and femur, cruciate ligament defects, meniscus injuries in sheep and horses. CT arthrography is recommended as a convenient imaging diagnostic method (Hontoir et al., 2017; Nelson et al., 2016). The surgery of femoropatellar and femorotibial joints in the sheep is still being developed in order to refine the least invasive method with the least possible post-operative complications (Orth and Madry, 2013).

\section{Material and Methods:}

The experiment was conducted on four female lambs aged between 6 months and 1 year, weighing about $30 \mathrm{~kg}$, of a mixed milky strain.

\section{Computer Morphology Research}

The lambs were anesthetized with xylazine - $0.25 \mathrm{mg} / \mathrm{kg}$ i.m., and, to deepen the narcosis - with thiopental sodium $6,6-8,8 \mathrm{mg} / \mathrm{kg}$ i.v. The animals had not been fed for $10-12$ hours before the observation. The animals were fixed in sternal recumbency. After providing operational access to $a$. femoralis, a 4F-thick and a $11.0 \mathrm{~cm}$ long arterial transradial catheter was introduced. Ultraviolet iodine 
contrast (ULTRAVIST ® $370769 \mathrm{mg} / \mathrm{ml}$ solution for injection / infusion iopromide) was injected through the catheter via an infusion pump - 0,5 $\mathrm{ml}$ per $1 \mathrm{sec}$. The computer-based imaging was performed by Picker ${ }^{\circledR}$ CT PQ 5000 spiral computerized tomograph. The CT scanning was performed in transverse planes starting from the middle of the femur to the middle of the tibia. The slices were at intervals of $2 \mathrm{~mm}$ and were $1.5 \mathrm{~mm}$ thick. The scanning was carried out by the DICOM Viewer computer software ${ }^{\circledR}$. Puncture holes were sutured. The animals recovered completely after the interventions.

\section{Results:}

The major blood vessels: the popliteal artery and vein, the lateral and the medial saphenous veins, were monitored in all CT images (slices) throughout the length of the knee joint and the two pelvic limbs of the sheep studied (Figures 1, 2, 3, 4).

In the CT image of the distal part of the femoropatellar joint a number of vessels that go through it are visualized: the saphenous artery is subcutaneous and cranial of the medial saphenous vein; the genicular artery and vein are positioned medially and deeply; and the caudal femoral artery is visualized laterally and is placed deeper than the lateral saphenous vein, between $\mathrm{m}$. gastrocnemius and $\mathrm{m}$. biceps femoris (Figure 1). These arteries are located proximally to the femoral artery.

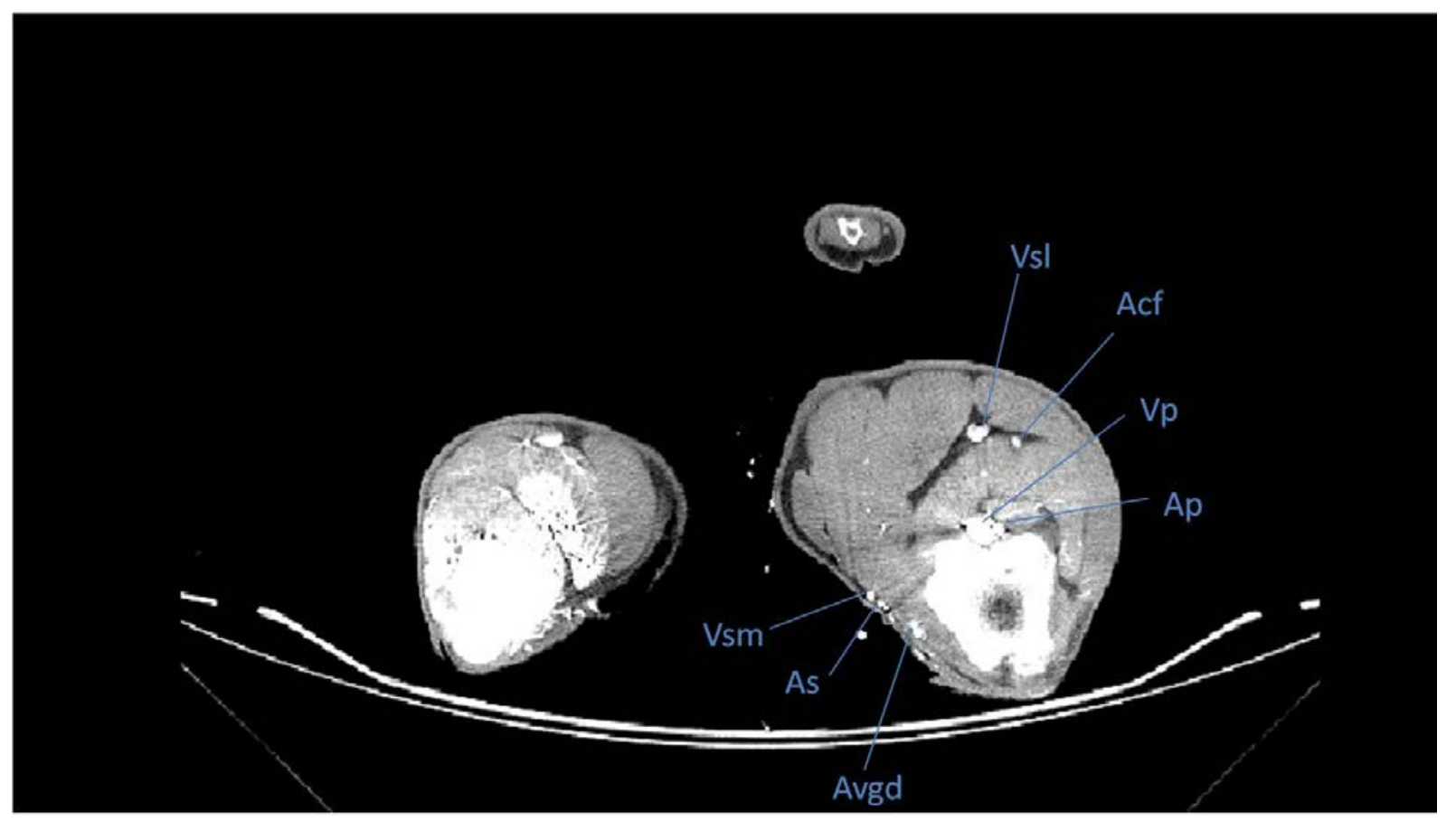

Fig. 1. CT image of the distal part of the femoropatellar joint of the left hindlimb of the sheep: Ap popliteal artery, Acf - caudal femoral artery, As - saphenous artery, VsI - lateral saphenous vein, Vsm - medial saphenous vein, Vp - popliteal vein, Avgd - descend genicular artery and vein. 
At the level of the femoral condyles of the sheep a. genus distalis lateralis and a.genus distalis medialis that branch from the popliteal artery in sheep are detected bilaterally (Fig. 2). Their continuations accompanied by the corresponding veins are registered caudally towards the femorotibial joint (Fig. 3). In the same slice, the saphenous artery is observed medially; and the caudal femoral artery and vein are observed laterally - under m. biceps femoris (Figure 3).

The same blood vessels with the same disposition but distal from the previous level are shown in the last CT image (Fig. 4). The terminal branches of $a$. and $v$. genus distalis lateralis and the medial eponymous artery and vein that supply the collateral ligaments and the muscles around them are also visualized in Fig. 4. The same figure shows the continuation of the left and right saphenous arteries and a. genus media (Fig. 4), which supply the knee joint cruciate ligaments in the sheep. This artery is identified at the level of the femorotibial joint, between the femoral condyles and the popliteal artery (Fig. 4). The knee veins are traced in the CT images from their origin to their opening into the popliteal vein.

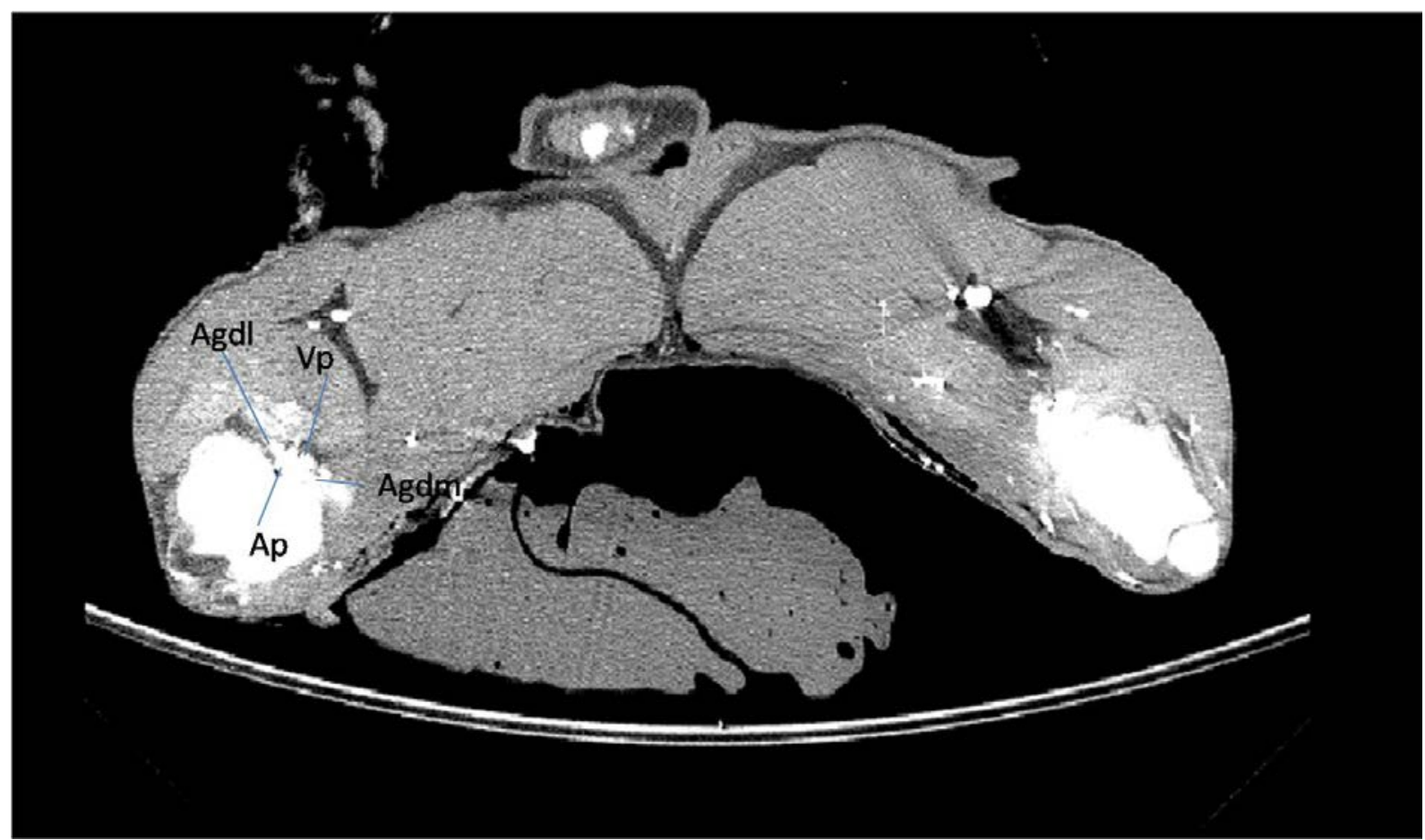

Fig. 2. CT image of the femoral condylies of the right hindlimb of the sheep - Ap - popliteal artery, Vp - popliteal vein, Agl - distal lateral genicular artery, Agdm - distal medial genicular artery. 


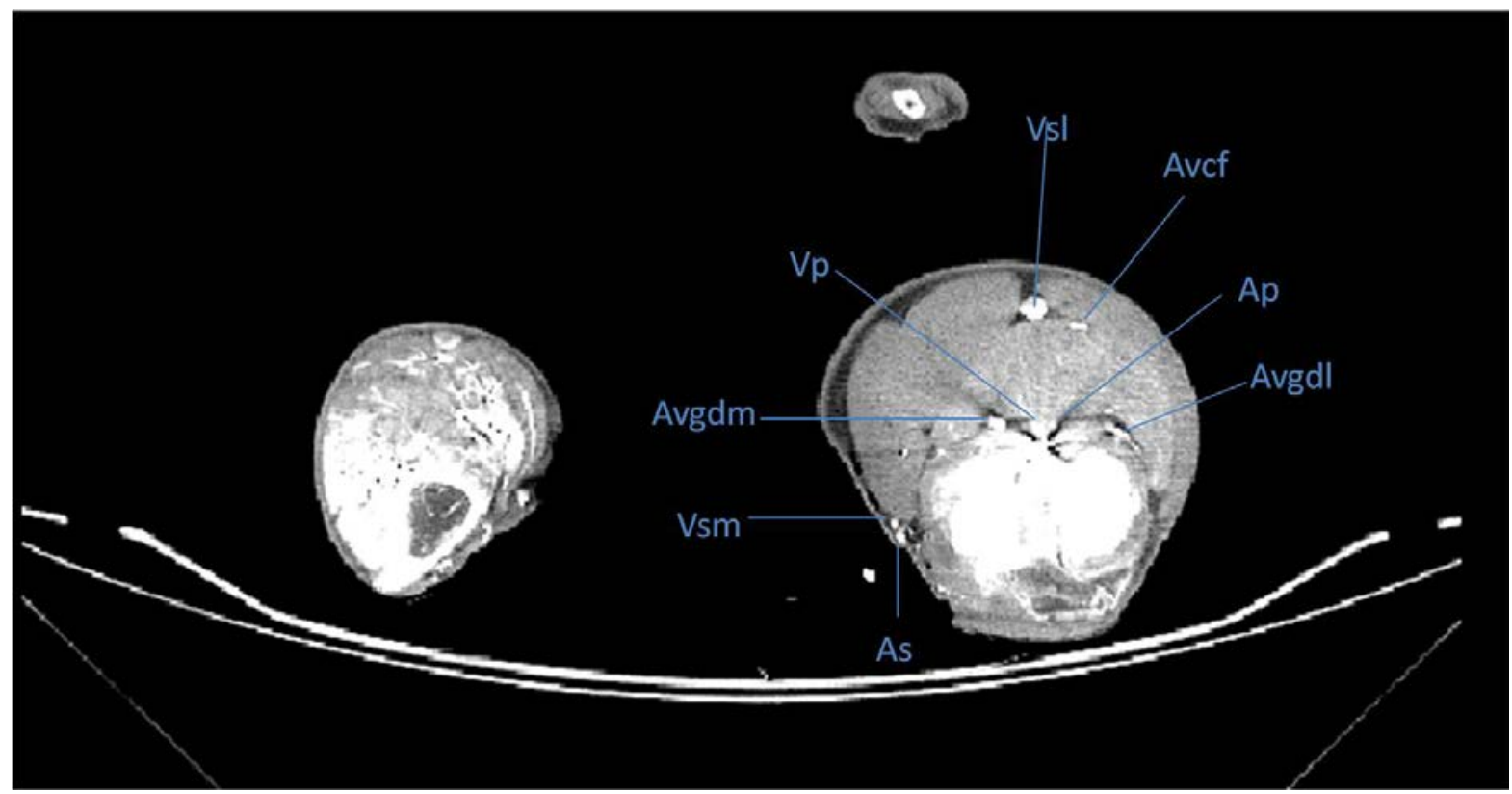

Fig. 3. CT image of the femorotibial joint of the left hindlimb of the sheep - Ap - popliteal artery, Avcf - caudal femoral artery and vein, As - saphenous artery, VsI - lateral saphenous vein, Vsm medial saphenous vein, Vp - popliteal vein, Avgdl - distal lateral genicular artery and vein, Avgdm - distal medial genicular artery and vein.

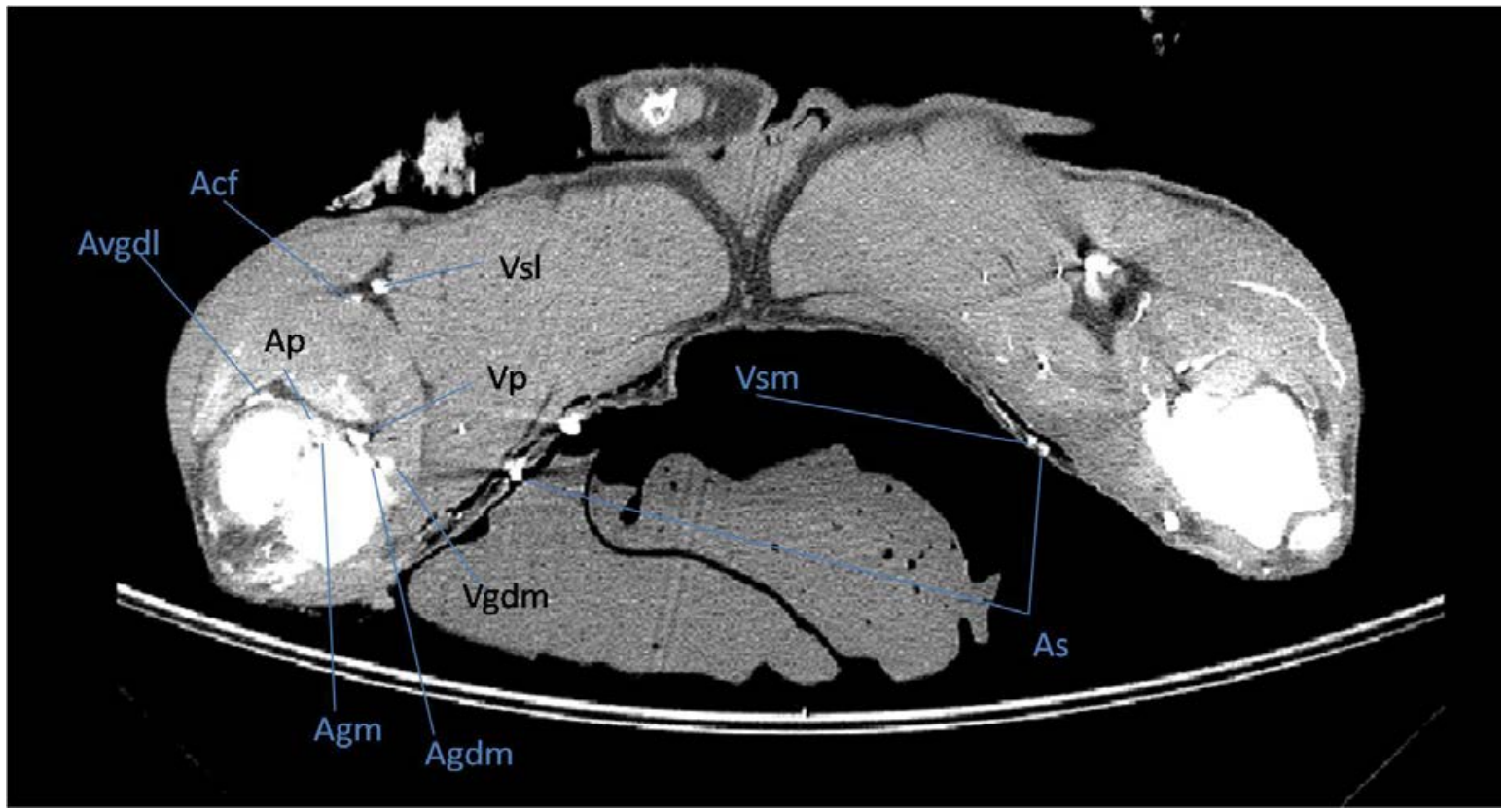

Fig. 4. CT image of the distal part of the femorotibial joint of the right hindlimb of the sheep - Ap popliteal artery, Avcf - caudal femoral artery, As - saphenous artery, VsI - lateral saphenous vein, Vsm - medial saphenous vein, Vp - popliteal vein, Avgdl - distal lateral genicular artery and vein, Agdm - distal medial genicular artery, Vgdm - distal medial genicular vein, Agm - middle genicular artery. 


\section{Discussion}

The popliteal artery accompanied by the eponymous vein are placed deeply below the corresponding muscle, between the femoral condyles and tibia (Getty, 1975; Schaller, 2007; Ashdown and Done, 2010). The artery is always placed lateral and the vein is always medial. This topography of the vessels is also described in horses (Ashdown and Done, 2010) and dogs (Done et al., 2009). In this study we confirmed the same topography in the sheep. In the knee area the femoral artery has three branches: the most proximal branch is a. saphena, followed by a. genus descendens, and the last branch is a. caudalis femoris. It is the place where the femoral artery continues as the popliteal artery (Getty, 1975; Schaller, 2007; Ashdown and Done, 2010). This artery accompanied by the eponymous vein and represented as a. and $v$. caudalis femoris distalis in the dog's pelvic limb has been detected by computed tomography (Georgiev et al., 2011). The main branches of the femoral artery in the sheep as well as a. caudalis femoris were visualized, traced and confirmed by the CT scans that we performed. In ruminants a. genus proximalis lateralis begins from a. caudalis femoris (Getty, 1975; Schaller, 2007) and together with a. circumflexa femoris medialis supplies blood to the deep popliteal lymph node in the sheep (Heath et al., 1983). We could not identify those arteries. Bilaterally aa. genus distalis medialis et lateralis are continuations of the popliteal artery and a. genus media is more distal from them (Getty, 1975; Schaller, 2007), which we observed too. A. genus media is directed cranially and supplies the femoropatelar joint and cranial cruciate ligaments, which are also supplied by a. genus descendens in sheep (Getty, 1975; Schaller, 2007; Ashdown and Done, 2010; Takroni et al., 1997). These two arteries were also detected by the authors of the present CT angiography. Besides them, in the area above the heads of $\mathrm{m}$. gastrocnemius a few aa. surales are detached from a. poplitea (Getty, 1975; Schaller, 2007), which we were unable to visualize.

The deep veins in the knee region flow into the popliteal vein (Getty, 1975; Schaller, 2007), which is easily tracked at the sequential CT images that we made. In the nomenclature the veins are denoted by one name - vv. genus (Schaller, 2007), but for the sake of clarity, we assigned to them the names of the corresponding arteries. The superficial veins that do not accompany in their course the eponymous arteries are v. saphena medials, and v. saphena lateralis, which is the biggest one in ruminants (Getty, 1975; Schaller, 2007; Ashdown and Done, 2010). It is visible in CT scan of the pelvic limb in the sheep too. According to May, 1955 a. saphena lies between the corresponding nerve and v. saphena medials, medial to the knee, the vein being caudally located, which we also observed. It is specific that in ruminants the lateral saphenous vein flows into v.circumflexa femoris medialis (Getty, 1975; Schaller, 2007), which is higher than the knee area, which we studied.

CT angiography of the knee joint in the sheep is a more advantageous method than the digital venography of cattle, sheep, goats (Santos et al., 2016) and goat's arteriography (Burns and Cornell, 1981; Nazhvani, 2007). By digital venography and arteriography one can observe either arteries or veins, while CT angiography allows simultaneous imaging of both parts of the circulatory system. The research of the digit vessels has been provoked by the various diseases of the fingers and the hoof in the ruminants that are more common than the knee joint injuries. (Gantke et al., 1998; Nazhvani et al., 2007). While the grounds of the present study is that the knee joint of the sheep can be used as a model for meniscal surgery in humans, which provides guidance for a wide variety of studies in this area and is carried out in the sheep (Takroni et al., 1997, Saitz et al., 1997 ; Chevrier et al., 2009). 


\section{Conclusion}

CT arthrography has been recommended by some authors for the diagnosis and monitoring of the jointcartilage defects of the knee joint in the sheep (Hontoir et al., 2017), which we can support based on the results of the present study of the blood vessels in this area. This communication enables us to point to this imaging method as extremely important for the recovery assessment after surgical manipulations and in cases of osteoarthritis of the knee joint in the sheep (Burger et al., 2007).

\section{References}

1. Ashdown R. R., and S. H. Done, 2010. Color atlas of Veterinary Anatomy: The Ruminant. Vol. 1. Mosby Elsevier Limited.135-160.

2. Ashdown R. R., and S. H. Done, 2011. Color atlas of Veterinary Anatomy: The Horse. Vol. 1. Mosby Elsevier Limited.135-160.

3. Boosman, R., F. Nemth, E. Gruys et al., 1989. Arteriographical and pathological changes in chronic laminitis in dairy cattle. Vet Q, 11:144-155.

4. Burns, J., C. Cornell, 1981. Angiography of the Caprine digit. Vet Radiol, 22:174-176.

5. Burger, C., M. Mueller, P. Wlodarczyk, H. Goost, R. H. Tolba, C. Rangger, K. Kabir, O. Weber, 2007. The sheep as a knee osteoarthritis model: early cartilage changes after meniscus injury and repair. Lab Anim., 41, 4, 420-31.

6. Chevrier, A., M. Nelea, M. B. Hurtig, C. D. Hoemann, M. D. Buschmann, 2009. Meniscus Structure in Human, Sheep, and Rabbit for Animal Models of Meniscus Repair. Wiley Periodicals, Inc, Journal of Orthopaedic Research, 1197-1203.

7. Done, S. H., P. C. Goody, S. A. Evans \& N. C. Stickland, 2009. Color Atlas of Veterinary Anatomy: The Dog and Cat, vol 3, Mosby Int.

8. Evans, H. E. \& A. De Lahunta, 2013. Miller's Anatomy of the Dog, 4th edn, Saunders and Elsevier.

9. Nazhvani, S. D., S. Abbasi, M. Tadjalli, 2007. Arteriographical Evaluation of Normal Digit and Hoof in Goat. Iranian Journal of Veterinary Surgery, 2, 4, 44-48.

10. Gantke, S., K. Nuss, R. Kostlin, 1998. Radiologic findings in bovine laminitis. Tierarztl Prax Ausg G Grosstiere Nutziere, 26: 239- 246.

11. Georgiev G. I., I. Raychev, G. D. Georgiev, N. Mehandziyski, L. Hristakiev, 2012. Morphologic study on the portal vessels system in sheep's liver. In: Procedings of the Conference Tradition 12. and Modernity in Veterinary Medicine, Sofia, Bulgaria, pp. 87-97 (BG).

12. Georgiev G. I., G. D. Georgiev, I. Raychev, N. Mehandziyski, 2011. Contrast computed tomography on the bones and major arteries in the canine pelvic limb. In: Procedings of the Conference Tradition and Modernity in Veterinary Medicine, Sofia, Bulgaria, pp. 36-42 (BG).

13. Getty, R., 1975. The Anatomy of the Domestic Animals. Sisson and Grossman eds. 5th ed. Vol 1. Philadelphia: WB Saunders Co., 994-1001.

14. Heath, T., R. Brandon, 1983. Lymphatic and blood vessels of the popliteal node in sheep. Anat Rec., 207(3):461-72.

15. Hontoir, F., P. Clegg, V. Simon, N. Kirschvink, J. F. Nisolle, J. M. Vandeweerd, 2017. Accuracy of computed tomographic arthrography for assessment of articular cartilage defects in the ovine stifle. Vet Radiol Ultrasound. doi: 10.1111/vru.

16. Joscht, M., M. Martin, M. Henin, J. F. Nisolle, N. Kirschvink, A. Dugdale, B. Godart, H. Coulon, V. Simon, F. Hontoir, R. Graffin, Y. De Raeve, J. M. Vandeweerd, 2016. Angiographic Anatomy of External Iliac Arteries in the Sheep. Anat Histol Embryol. 45(6):443-449. 
17. Maclean, C.W., 1970. A post-mortem x-ray study of laminitis in barely beef animals. Vet Rec 86:457-462.

18. May, N. D. S., 1955. The Anatomy of the Sheep. Watson, Ferguson and Company, Q. Brisbane.' 116-136

19. Nelson, B.B, C. E. Kawcak, L. R. Goodrich, N. M. Werpy NM, A. Valdés-Martínez, C. W. Mcllwraith, 2016. Comparison between computed tomographic arthrography, radiography, ultrasonography, and arthroscopy for the diagnosis of femorotibial joint disease in western performance horses. Vet Radiol Ultrasound. 57, 4, 387-402.

20. Orth, P. and H. Madry, 2013. A low morbidity surgical approach to the sheep femoral trochlea. BMC Musculoskelet Disord. 3;14:5.

21. Santos, I. F. C., C. A. Hussni, C. A. Rodrigues, M. J. Watanabe and A. L. G. Alves, 2016. Digital venography in ruminants - a review. Veterinary Quarterly, 36, 1, 22-29.

22. Schaller, O., 2007. Angiology, Veins. In: Illustrated Veterinary Anatomical Nomenclature, 2nd edn, Ferdinand Enke Verlag, Stuttgart.

23. Seitz, H., T. Hausner, I. Schlenz, S. Lang, J. Eschberger, 1997. Vascular anatomy of the ovin anterior cruciate ligament. Archives of Orthopaedic and Trauma Surgery, 116, 1-2, 19-21.

24. Takroni, T., L. Laouar, A. Adesida, A. Janet, W. Elliott and N. M. Jomha, 2016. Anatomical study: comparing the human, sheep and pig knee meniscus. J Exp Orthop, 3: 35.

25. Vermunt, J.J., P. R. Greenough, 1994. Predisposing factors of laminitis in cattle. Br Vet J , 150 : 151-164.

\section{Corresponding author:}

Dr. Iliana Ruzhanova, DVM, Faculty of Veterinary Medicine, University of Forestry

P.O. Box 1756 , Sofia, "Kliment Ohridsky" str.10, tel: +359 898541056

email: iliana_ruzhanova@ltu.bg 